(c) American Dairy Science Association, 2006.

\title{
Prediction of Dry Matter Intake Throughout Lactation in a Dynamic Model of Dairy Cow Performance
}

\author{
J. L. Ellis, ${ }^{1}$ F. Qiao, ${ }^{2}$ and J. P. Cant \\ Center for Nutrition Modeling, Department of Animal and Poultry Science, University of Guelph, Guelph, ON, Canada N1G 2W1
}

\begin{abstract}
In the dynamic modeling of dairy cow performance over a full lactation, the difference between net energy intake and net energy used for maintenance, growth, and output in milk accumulates in body reserves. A simple dynamic model of net energy balance was constructed to select, out of some common dry matter intake (DMI) prediction equations, the one that resulted in a minimum cumulative bias in body energy deposition. Dry matter intake was predicted using the Cornell Net Carbohydrate and Protein System, Agricultural Research Council, or National Research Council (NRC) DMI equations from body weight (BW) and predicted fat-corrected milk yield. The instantaneous BW of cows at progressive weeks of lactation was simulated as the numerical integral of the BW change obtained from the predicted net energy balance. Predicted DMI and BW from each DMI equation, using either of 2 equations to describe maintenance energy expenditures, were compared statistically against observed data from 21 herd average published full lactation data sets. All DMI equations underpredicted BW and DMI, but the NRC DMI equation resulted in the minimum cumulative error in predicted BW and DMI. As a general solution to prevent predicted BW from deviating substantially over time from the observed BW, a lipostatic feedback mechanism was integrated into the NRC DMI equation as a 2-parameter linear function of the relative size of simulated body reserves and week of lactation. Residual sum of squares was reduced on average by $52 \%$ for BW predictions and by $41 \%$ for DMI predictions by inclusion of the negative feedback with parameters taken from the average of all 21 least squares fits. Similarly, root mean square prediction error (\%) was reduced by $30 \%$ on average for BW predictions and by $23 \%$ for DMI predictions. Inclusion of a feedback of energy reserves onto predicted DMI, simulating lipostatic regulation of BW, solved the problem of final BW deviation within a
\end{abstract}

\footnotetext{
Received June 27, 2005.

Accepted November 10, 2005.

${ }^{1}$ Corresponding author: jellis@uoguelph.ca

${ }^{2}$ Current address: Beijing Earth-Tech Advantages Inc., Beijing, China 100085.
}

dynamic model and improved its DMI prediction to a satisfactory level.

Key words: intake prediction, energy balance, dairy cow

\section{INTRODUCTION}

Dynamic computer modeling techniques allow one to simulate the daily performance of a dairy cow throughout an entire lactation. Such simulations can be used to evaluate and formulate diets and entire feeding programs at the farm level. Typically, instantaneous milk production rates are calculated from rates of nutrient flow from the diet. Because of the many variables that can affect DMI (NRC, 1987, 1988) and the sensitivity of model predictions to voluntary DMI, it is usually input as a measured value (Baldwin et al., 1987; Dijkstra et al., 1996). However, voluntary DMI is under the control of the animal and is part of the dietary response of the animal, so it has been argued that to not predict DMI is to ignore a large part of feed evaluation (Van der Honing, 1998).

For the lactating dairy cow, the plethora of DMI prediction equations that exists in the literature can be subdivided into regression equations, complex systems, and fill systems (Ingvartsen, 1994). Because of their commonality and ease of handling, simple regression equations could potentially be used in dynamic modeling of lactating cow performance. Examples of regression equations are those of the Agricultural Research Council (ARC; 1980), the Cornell Net Carbohydrate and Protein System (CNCPS; Fox et al., 2004), and the NRC (2001), which are all intended to be used in static evaluations of nutritional adequacy of a diet and in diet formulation. Independent variables required for solution of these equations include $\mathrm{BW}$ and milk production. Therefore, where BW and milk production are predicted values in a dynamic model, a circular problem arises in the simulated energy balance of the animal. When the difference between observed intake and estimated net energy utilized for maintenance and lactation was allowed to accumulate in BW, predicted BW rapidly deviated from its observed value as lactation progressed (Ellis et al., 2006). Part of the error was attributed to underestimation of maintenance energy 
expenditures because of the effect of lactation on organ size and activity; therefore, a new time-independent equation, $0.096 \mathrm{Mcal}$ of $\mathrm{NE}_{\mathrm{I}} / \mathrm{kg}$ of $\mathrm{BW}^{0.75}$, as well as a time-dependent equation related to week of lactation (WOL) were developed by least squares fits to a set of 21 lactation curves to encompass this error. Using the same sets of data and with the revised descriptions of maintenance, the first objective of the current work was to evaluate the DMI predictions of the ARC, CNCPS, and NRC equations over the course of a full lactation according to BW predictions by a dynamic model of energy balance.

As a solution to prevent excessive accumulation of energy in the body, we sought to account for mechanisms that may operate in the animal. Voluntary DMI in ruminants has been shown to be negatively correlated with body fatness at any given physiological state (Coppock et al., 1972; Bines, 1979; Garnsworthy, 1988; Ingvartsen et al., 1995; Broster and Broster, 1998). Kennedy (1953) proposed a lipostatic theory according to which a peripheral signal produced in proportion to the amount of adipose tissue in the body signals to the brain the amount of energy stored in the body. This signal is then compared with a set point value, and deviations from the set point result in changes to energy intake or expenditures to return adipose stores to the predetermined level. The NRC (1988) made mention of this as a valid operating principal in the dairy cow. The discovery of leptin as an adipose hormone that negatively influences DMI (Zhang et al., 1994) was predicted by the lipostatic theory.

Incorporation of the lipostatic theory into a dynamic model of energy balance would provide connectivity among BW, BW change, and DMI. Dry matter intake could be adjusted according to a deviation of BW from its set point, potentially resulting in better BW and DMI predictions. Therefore, the second objective of the current work was to account for the effect of adiposity by incorporating a negative feedback loop of predicted body energy reserves onto predicted DMI.

\section{MATERIALS AND METHODS}

\section{Data Sets}

The observations against which the DMI equations were evaluated were the same 777 data points from 21 sets of lactation performance data averaged from herds of 9 to 22 cows used for maintenance energy expenditure equation development (Ellis et al., 2006). Information about the data sets is given in the companion article (Ellis et al., 2006). Criteria for data set selection were that weekly BW, DMI, and FCM production for at least 35 WOL were reported and that information was given on parity and diet.
A

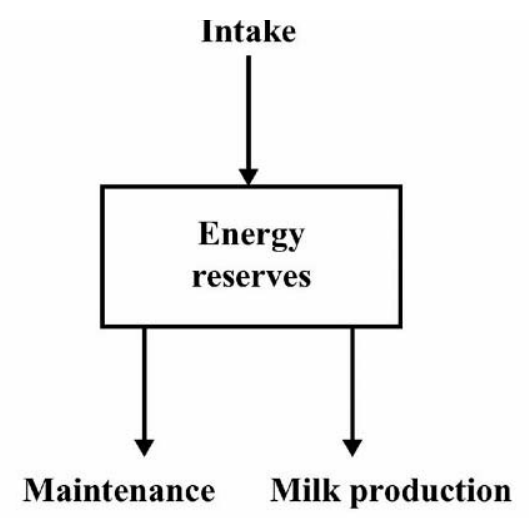

B

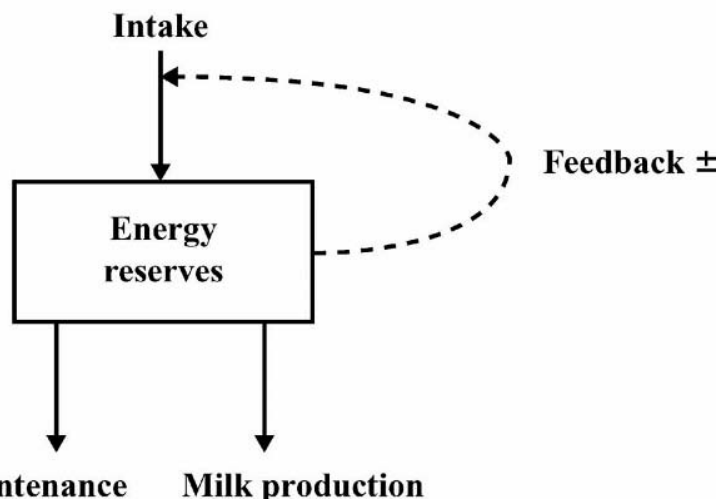

Figure 1. Unmodified (A) and modified (B) model of energy flows used to evaluate and correct the DMI equations. Solid arrows represent energy flows (measured in Mcal of $\mathrm{NE}_{\mathrm{L}} / \mathrm{d}$ ); the box represents a state variable (measured in Mcal of $\mathrm{NE}_{\mathrm{L}}$ ).

\section{Dynamic Energy Balance Model}

The approach taken to evaluate the DMI prediction equations was to use a lactation curve equation to obtain daily FCM production values, which were used as driving variables for the DMI prediction equations. Considering maintenance expenditures as a function of predicted BW, the implied deficit or excess of net energy was allowed to accumulate in the body to generate a time course of BW predictions throughout lactation, which were compared statistically with observed BW. A simple dynamic model of energy balance (Figure 1a) was written in Advanced Continuous Simulation Language (ACSL, 1994-1998), where, at any moment in time,

$$
\mathrm{dER} / \mathrm{dt}=\mathrm{NEI}-\mathrm{NE}_{\mathrm{L}}-\mathrm{NE}_{\mathrm{M}}
$$

where all net energy flows are in Mcal of $\mathrm{NE}_{\mathrm{L}} / \mathrm{d}$, dER/ $\mathrm{dt}$ is the instantaneous change in body energy reserves 
per day (net energy balance), and NEI is net energy intake. The net energy equivalents of body mass according to NRC (1988) were assumed so that BW change in kilograms per day was 0.203 times $\mathrm{dER} / \mathrm{dt}$ (Equation 1) if the balance was negative and 0.195 times $\mathrm{dER} / \mathrm{dt}$ if the balance was positive. The NRC (1988) factors were used because information on BCS, required for the NRC (2001) factors, was not available. Analysis showed the model was relatively insensitive to the differences between the NRC (1988) and NRC (2001) factors (Ellis et al., 2006); therefore, the single NRC (1988) factors were used. The instantaneous BW of cows at progressive WOL was simulated as the numerical integral of the BW change from an initial value of the observed BW at WOL 2, according to a fourth-order Runge Kutta algorithm with a step size of $0.01 \mathrm{~d}$.

Net energy intake was calculated as DMI $(\mathrm{kg} / \mathrm{d})$ multiplied by the net energy content of the feed, where net energy content of the feed was calculated weekly using the NRC (2001) computer program.

Dry matter intake was predicted by the equations of the NRC (2001)

$$
\begin{gathered}
\text { DMI }(\mathrm{kg} / \mathrm{d})=[(0.372 \times \mathrm{FCM}) \\
\left.+\left(0.0968 \times \mathrm{BW}^{0.75}\right)\right] \times\left(1-\mathrm{e}^{(-0.192 \times(\mathrm{WOL}+3.67))}\right),
\end{gathered}
$$

ARC (1980)

$$
\begin{gathered}
\text { DMI }(\mathrm{kg} / \mathrm{d})=\left[\left((135 / 1,000) \times \mathrm{BW}^{0.75}\right)\right. \\
+(\mathrm{FCM} \text { adjustment factor } \times 0.2)] \times(\mathrm{RIF} / 100)
\end{gathered}
$$

and CNCPS (Fox et al., 2004)

$$
\begin{gathered}
\text { DMI }(\mathrm{kg} / \mathrm{d})= \\
(0.0185 \times \mathrm{BW}+0.305 \times \mathrm{FCM}) \times \mathrm{LAG}
\end{gathered}
$$

where $\mathrm{FCM}=4 \% \mathrm{FCM}(\mathrm{kg} / \mathrm{d}), \mathrm{BW}=$ predicted $\mathrm{BW}(\mathrm{kg})$, $\mathrm{RIF}=$ relative intake factor, and $\mathrm{LAG}=1-$ $\mathrm{e}^{-[(0.564-0.124 \times \mathrm{PKMK}) \times(\mathrm{WOL}+\mathrm{P})]}$, where PKMK $=$ month postcalving when peak milk yield occurred $(1,2$, or 3$)$ and $P=2.36$ for PKMK $=1$ and 2 and $P=3.67$ for $\mathrm{PKMK}=3$.

For use of the ARC (1980) equation in a continuous simulation, discrete RIF values were plotted against WOL and fit to a lactation curve equation (Rook et al., $1993)$ to yield $\mathrm{RIF}=1.3596 \times(1-0.5138 \times$ $\left.\mathrm{e}^{-0.1335 \times \text { WOL }}\right) \times \mathrm{e}^{-0.00999 \times \text { WOL }}$. For this fit, $\mathrm{R}^{2}=0.9835$, average $\mathrm{SEM}=1.18$, and root mean square prediction error $($ MSPE; \%) $=1.060$.

Net energy for milk production was calculated as FCM $(\mathrm{kg} / \mathrm{d}) \times 0.749 \mathrm{Mcal} / \mathrm{kg}(\mathrm{NRC}, 2001)$. To avoid discontinuities in the simulation of $\mathrm{NE}_{\mathrm{L}}$ that would occur with weekly observations of FCM production as input, parameters of the lactation curve of Rook et al. (1993)

$$
\operatorname{FCM}(\mathrm{kg} / \mathrm{d})=\mathrm{A} \times\left(1-\mathrm{b}_{0} \times \mathrm{e}^{-\mathrm{b}_{1} \times \mathrm{t}}\right) \times\left(\mathrm{e}^{-\mathrm{c} \times \mathrm{WOL}}\right)
$$

were estimated with SAS PROC NLIN (SAS Inst., Inc., Cary, NC) for each data set from the weekly observations. Any lactation curve equation would have sufficed in this regard, and Equation 5 was simply chosen as one readily available and demonstrated to have been superior to others in fits to data (Rook et al., 1993). The fitting procedure did not converge on parameter estimates for data sets $1,4,7,8,9,12,13$, and 16; therefore, an exponential curve was fitted to FCM production data from WOL 20 onward. The exponential parameter from this curve was then used as the value for $c$ and set as a constant in the estimation of $A, b_{0}$, and $b_{1}$ from the entire lactation curve. The 21 curves were fit with an average root MSPE of $5.927 \%$ of the mean FCM yield (where $99.6 \%$ of MSPE was from random sources); the slope $(1.007 \pm 0.0106)$ and intercept $(-0.306 \pm 0.233)$ of the predicted vs. observed FCM plots did not significantly differ from 1 and 0 , respectively.

Net energy for maintenance was calculated from a time-independent equation as $\mathrm{NE}_{\mathrm{M}}=0.096 \mathrm{Mcal}$ of $\mathrm{NE}_{\mathrm{L}} / \mathrm{d}$ per $\mathrm{kg}$ of $\mathrm{BW}^{0.75}$ or from a time-dependent quadratic equation related to WOL as $\mathrm{NE}_{\mathrm{M}}=$ $\left[0.0227( \pm 0.0098) \times \mathrm{WOL}^{2}+1.352( \pm 0.456) \times \mathrm{WOL}+\right.$ $78.09( \pm 4.92) \mathrm{Mcal} / \mathrm{d}$ per $\mathrm{kg}$ of $\left.\mathrm{BW}^{0.75}\right] \times 10^{-3}$ according to Ellis et al. (2006). A $12.9 \%$ increase in $\mathrm{NE}_{\mathrm{M}}$ expenditures was applied to first-parity cows according to the difference in coefficients recommended by NRC (2001) for heifers of BCS $3.5\left(0.0903 \mathrm{Mcal}\right.$ of $\mathrm{NE}_{\mathrm{L}} / \mathrm{kg}$ of $\left.\mathrm{BW}^{0.75}\right)$ and for cows $\left(0.080 \mathrm{Mcal}\right.$ of $\mathrm{NE}_{\mathrm{L}} / \mathrm{kg}$ of $\left.\mathrm{BW}^{0.75}\right)$.

\section{Modified Dynamic Energy Balance Model}

A modified version of the original energy balance model with a lipostatic feedback on DMI (Figure 1b) was developed in Advanced Continuous Simulation Language in which

$$
\mathrm{DMI}_{\text {new }}(\mathrm{kg} / \mathrm{d})=
$$

DMI predicted by equation - feedback,

$$
\begin{aligned}
\mathrm{NEI}= & \mathrm{NE} \text { content of the feed } \\
& \times \mathrm{DMI}_{\text {new }}(\mathrm{kg} / \mathrm{d}),
\end{aligned}
$$

and

$$
\begin{gathered}
\text { Feedback }=[\mathrm{k} 1 \times \mathrm{WOL}+\mathrm{k} 2] \\
\times[(\mathrm{ER}-\mathrm{iER}) / \mathrm{iER}]
\end{gathered}
$$


Table 1. Statistics of BW and DMI predictions of the dynamic model using the 3 DMI equations [NRC (2001), Agricultural Research Council (ARC; 1980), Cornell Net Carbohydrate and Protein System (Fox et al., 2004)] and maintenance descriptions (Ellis et al., 2006)

\begin{tabular}{|c|c|c|c|c|c|c|c|c|}
\hline Prediction & Model & \multicolumn{2}{|c|}{ Predicted $^{1}$} & $\begin{array}{l}\text { Root } \\
\text { MSPE }^{2}\end{array}$ & \multicolumn{2}{|c|}{ MSPE } & $\mathrm{ED}^{5}$ & $\mathrm{RSS}^{6}$ \\
\hline \multicolumn{9}{|c|}{$-(\%)$} \\
\hline \multirow{2}{*}{0.096 time-independent maintenance equation $^{7}$} & $\mathrm{ARC}$ & 543.5 & 2.8 & 9.4 & 7.7 & 40.3 & 52.1 & $2.1 \mathrm{M}$ \\
\hline & NRC & $538.6^{*}$ & 2.6 & 7.4 & 22.5 & 29.5 & 48.1 & $1.3 \mathrm{M}$ \\
\hline Time-dependent maintenance equation ${ }^{8}$ & CNCPS & $536.4^{*}$ & 3.1 & 9.8 & 15.6 & 48.7 & 35.9 & $2.3 \mathrm{M}$ \\
\hline \multicolumn{9}{|l|}{ DMI } \\
\hline \multirow[t]{3}{*}{0.096 time-independent maintenance equation ${ }^{7}$} & CNCPS & $15.6^{*}$ & 0.1 & 16.1 & 50.9 & 22.0 & 27.1 & 6,040 \\
\hline & ARC & $16.4^{*}$ & 0.1 & 12.7 & 28.2 & 21.3 & 50.6 & 3,748 \\
\hline & $\mathrm{NRC}$ & $16.7 *$ & 0.1 & 11.4 & 18.3 & 28.9 & 52.9 & 3,050 \\
\hline \multirow{3}{*}{ Time-dependent maintenance equation ${ }^{8}$} & CNCPS & $15.9^{*}$ & 0.1 & 15.0 & 39.4 & 29.1 & 31.6 & 5,240 \\
\hline & ARC & $16.5^{*}$ & 0.1 & 11.9 & 27.8 & 20.5 & 51.8 & 3,298 \\
\hline & NRC & $16.8^{*}$ & 0.1 & 11.5 & 17.2 & 31.9 & 50.9 & 3,107 \\
\hline
\end{tabular}

${ }^{1}$ Average predicted BW over all weeks of lactation $(\mathrm{n}=21)$.

${ }^{2}$ Root mean square prediction error (MSPE) expressed as a percentage of the observed mean.

${ }^{3}$ Error due to bias; percentage of total MSPE.

${ }^{4}$ Error due to regression; percentage of total MSPE.

${ }^{5}$ Error due to disturbance; percentage of total MSPE.

${ }^{6} \mathrm{RSS}=$ residual sum of squares $\left[\Sigma(\text { predicted }- \text { observed })^{2}\right]$.

${ }^{7}$ Maintenance energy expenditures calculated as $\mathrm{NE}_{\mathrm{M}}=0.096 \mathrm{Mcal}$ of $\mathrm{NE}_{\mathrm{L}} / \mathrm{kg}$ of $\mathrm{BW}^{0.75}$.

${ }^{8}$ Maintenance energy expenditures calculated as $\mathrm{NE}_{\mathrm{M}}=\left[-0.0227( \pm 0.0098) \times \mathrm{WOL}^{2}+1.352( \pm 0.456) \times \mathrm{WOL}+78.09( \pm 4.92) \mathrm{Mcal}_{\mathrm{of}} \mathrm{NE} /\right.$ $\mathrm{kg}$ of $\left.\mathrm{BW}^{0.75}\right] \times 10^{-3}$, where WOL $=$ week of lactation.

*Predicted mean is significantly different from the observed mean (observed BW mean $=558.2 \pm 3.4$; observed DMI mean $=17.6 \pm 0.1$; $P<0.05)$.

where ER (Mcal of $\mathrm{NE}_{\mathrm{L}}$ ) is the integral of Equation 1, giving current body energy reserves, and $\mathrm{iER}$ is the initial energy reserves, set to $1.11 \times$ initial empty BW according to the relationship between BCS and fat content of the empty body developed by Fox et al. (1999) for a BCS of 3.5. Estimates of k1 and k2 feedback parameters were obtained for each of the 21 data sets with an iterative Levenberg-Marquardt algorithm to find lowest residual sums of squares (RSS) between predicted and observed weekly BW across 35 WOL.

\section{Statistical Analysis}

Mean square prediction error for each of the 21 data sets was calculated as

$$
\operatorname{MSPE}=\sum_{i=1}^{n}\left(\mathrm{O}_{\mathrm{i}}-\mathrm{P}_{\mathrm{i}}\right)^{2} / \mathrm{n}
$$

where $\mathrm{n}$ is the number of observations, $\mathrm{O}_{\mathrm{i}}$ is the observed value, and $P_{i}$ is the predicted value. Square root of the MSPE, expressed as a proportion of the observed mean, gave an estimate of the overall prediction error. The MSPE was decomposed into random error, error caused by deviation of the regression slope from unity, and error caused by overall bias (Bibby and Toutenburg, 1977).
The BW and DMI predictions were also evaluated by examining the slope and intercept of the regression of predicted values on observed. Using PROC MEANS in SAS (SAS Inst., 2000), the average slopes and intercepts were tested for significant difference from the line of unity (slope of 1 , intercept of 0 ). Residual BW and DMI (predicted - observed) were tested against WOL, and the average linear and quadratic coefficients of the plots were tested against zero using PROC MEANS in SAS to identify patterns of bias in the predictions. Mean predicted BW and DMI values were compared against observed values by using the $t$-test.

The DMI prediction equation that resulted in the best BW and DMI predictions within the unmodified model (Figure 1a) according to this analysis was selected for inclusion in the modified energy balance model (Figure 1b); however, similar parameterization could be done with any DMI prediction equation.

\section{RESULTS}

\section{Evaluation of BW and DMI Predictions of the 3 DMI Prediction Equations in the Unmodified Dynamic Model of Energy Balance}

Mean predicted BW was significantly lower than the observed values for the CNCPS and NRC equations and 

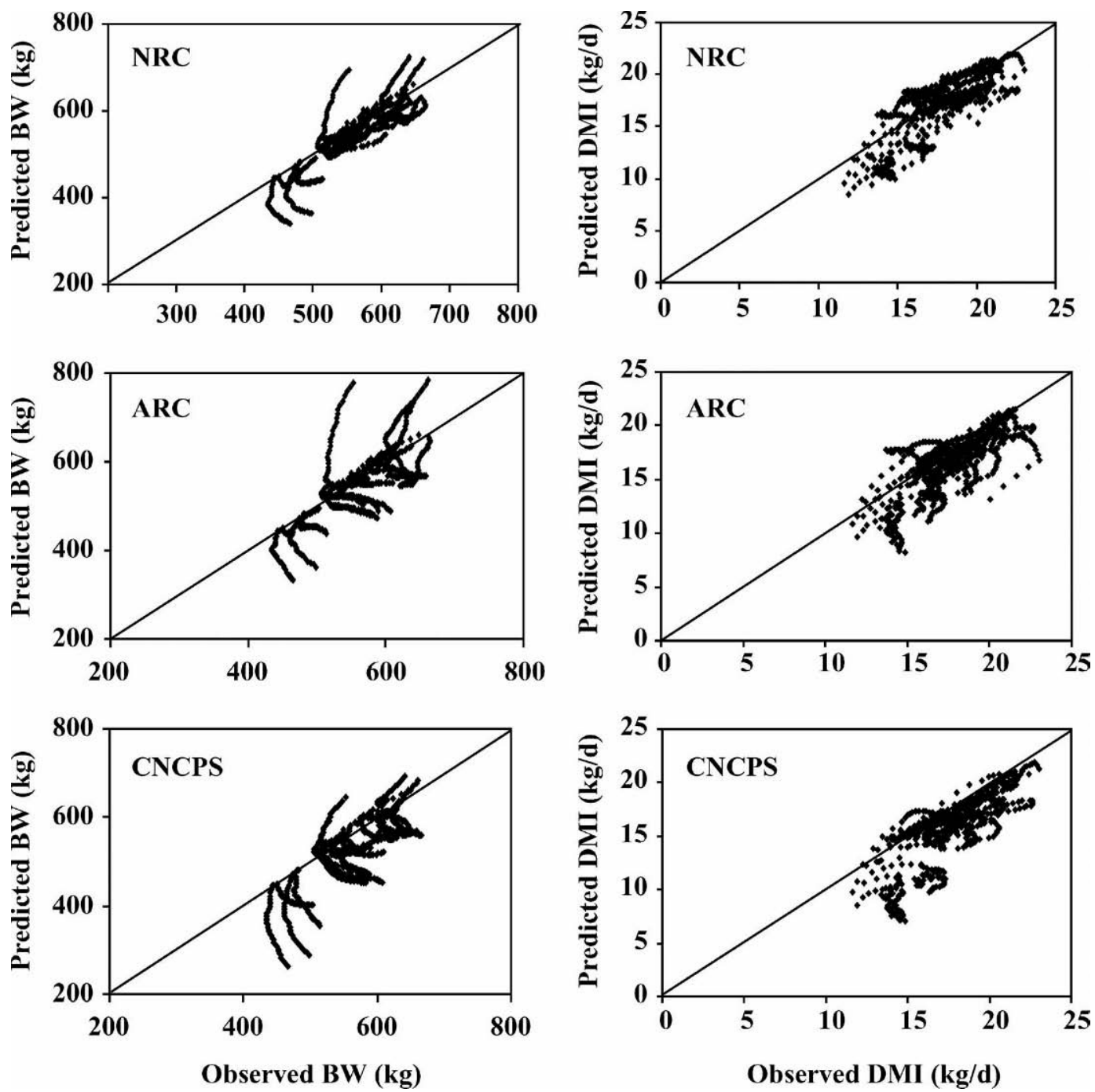

Figure 2. Predicted vs. observed BW (kg; left three graphs) and predicted vs. observed DMI (kg/d; right three graphs) tested against the line of equality for the 3 DMI equations [NRC (2001), Agricultural Research Council (ARC; 1980), and Cornell Net Carbohydrate and Protein System (CNCPS; Fox et al., 2004)] in the energy balance model (Figure 1a) when maintenance energy expenditures were calculated as a time-independent equation $\left(0.096 \mathrm{Mcal}\right.$ of $\mathrm{NE}_{\mathrm{L}} / \mathrm{kg}$ of $\left.\mathrm{BW}^{0.75}\right)$.

was accompanied by a significant underprediction of DMI by each of the 3 DMI equations for both estimations of maintenance (Table 1; Figure 2). Analysis of predicted vs. observed plots showed that BW predictions for every scenario, except for the NRC equation with the 0.096 time-independent maintenance equation, deviated significantly from the line of unity (Figures 2 and 3). The predicted vs. observed DMI plots for each of the DMI equations with the 0.096 timeindependent maintenance equation, as well as the CNCPS equation with the time-dependent maintenance equation, were also significantly different from the line of unity (Figures 2 and 3 ).
Analysis of the residuals showed, for the most part, significant WOL effects (Figures 4 and 5) and a trend for error to accumulate in BW as WOL progressed.

The NRC (2001) DMI equation resulted in the lowest level of error. Root MSPE percentages for the NRC equation were 7.4 and 7.7 for BW predictions using the time-independent maintenance equation and the timedependent maintenance equation, respectively, and 11.4 and 11.5 for DMI predictions using the time-independent maintenance equation and the time-dependent maintenance equation, respectively (Table 1). Composition of MSPE for BW and DMI predictions was variable between DMI equations. However, for the NRC (2001) 

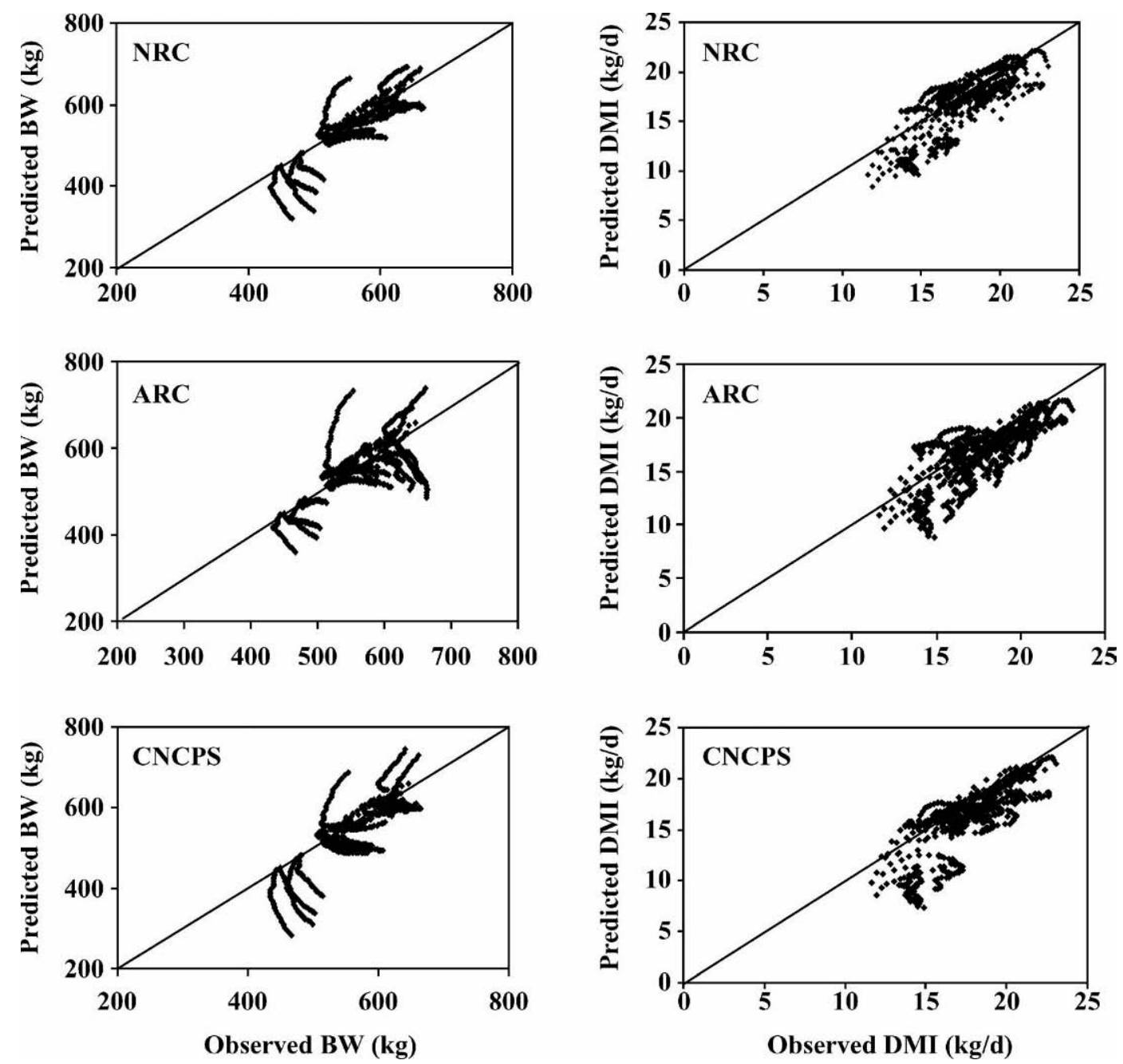

Figure 3. Predicted vs. observed BW (kg; left three graphs) and predicted vs. observed DMI (kg/d; right three graphs) tested against the line of equality for the 3 DMI equations [NRC (2001), Agricultural Research Council (ARC; 1980), Cornell Net Carbohydrate and Protein System (CNCPS; Fox et al., 2004)] in the energy balance model (Figure 1a) when maintenance energy expenditures were calculated as a time-dependent equation related to week of lactation $\left\{\mathrm{WOL} ;\left[\mathrm{NE}_{\mathrm{M}}=\left(-0.0227( \pm 0.0098) \pm \mathrm{WOL}^{2}+1.352( \pm 0.456) \times \mathrm{WOL}+78.09( \pm 4.92) \mathrm{Mcal}\right.\right.\right.$ of $\mathrm{NE}_{\mathrm{L}} / \mathrm{kg}$ of $\left.\left.\mathrm{BW}^{0.75}\right) \times 10^{-3}\right]$.

and ARC (1980) equations, the largest proportion of MSPE was from random sources (Table 1). The NRC (2001) equation yielded the lowest RSS for both BW and DMI predictions, with either description of maintenance (Table 1).

For the CNCPS (2004) and ARC (1980) DMI equations, describing maintenance as a time-dependent function of WOL resulted in the lowest RSS and root MSPE for both BW and DMI predictions (Table 1). However, for the NRC (2001) DMI equation, the 0.096 timeindependent maintenance equation resulted in the lowest RSS and root MSPE (Table 1).

The NRC (2001) equation yielded the best overall BW and DMI predictions from the dynamic simulation of energy balance according to MSPE, RSS, and residual plots, and for this reason, it was selected as the example equation to use in the modified feedback model (Figure 1b). Because the time-independent maintenance equation yielded the best predictions for the NRC (2001) DMI equation, but the time-dependent maintenance equation gave the best predictions for the ARC (1980) and CNCPS (2003) equations, both descriptions of maintenance were moved forward into development of a modified energy balance model. The procedure could be repeated for any DMI prediction equation of the regression type and would yield similar results in terms of overall model behavior, although least squares parameters of the feedback would certainly differ. 

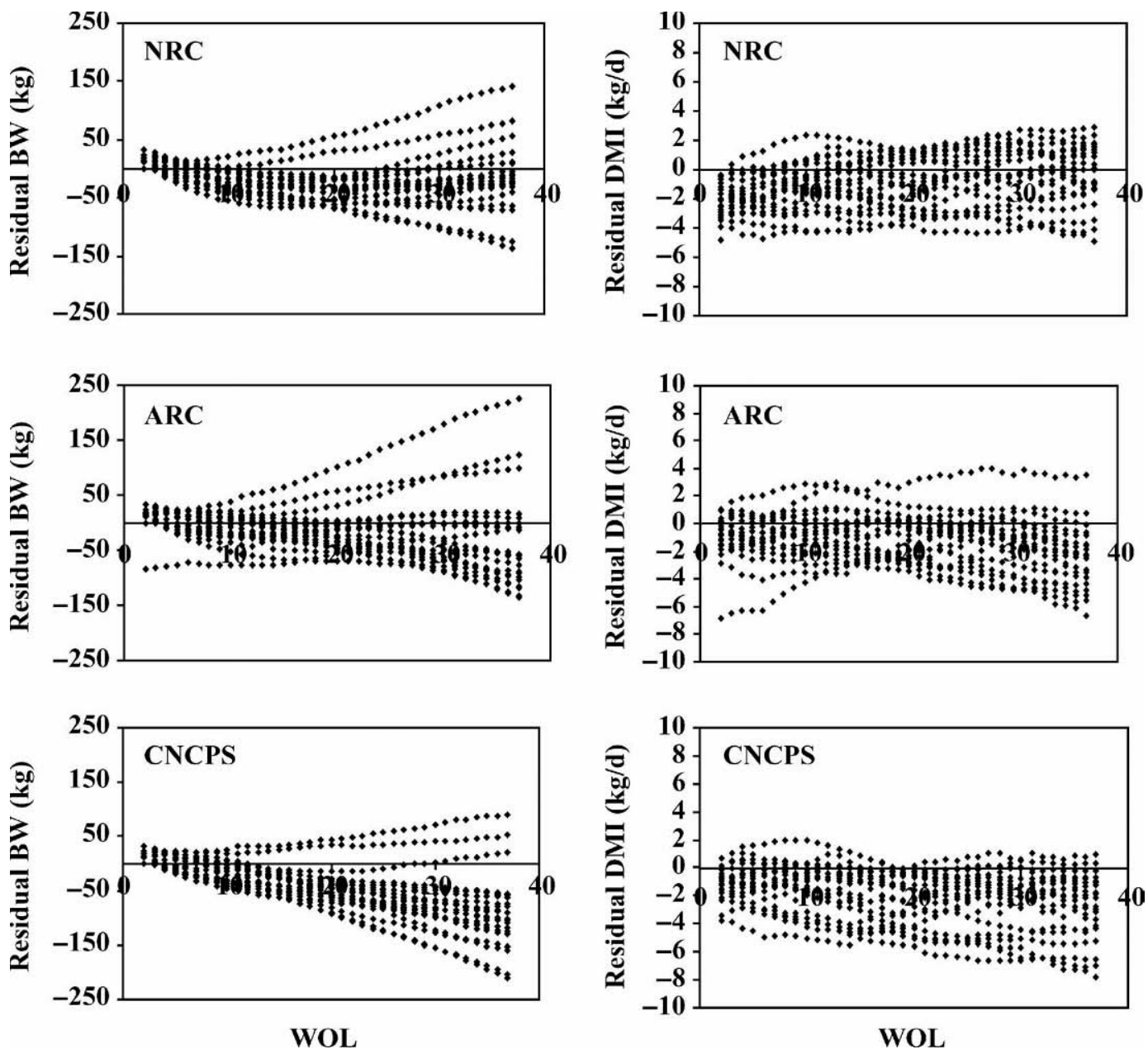

Figure 4. Relationship between residual (predicted - observed) and week of lactation (WOL) for BW (kg; left three graphs) and DMI (kg/d; right three graphs) for the 3 DMI equations [NRC (2001), Agricultural Research Council (ARC; 1980), Cornell Net Carbohydrate and Protein System (CNCPS; Fox et al., 2004)] in the energy balance model (Figure 1a) when maintenance energy expenditures were calculated as a time-independent equation $\left(0.096 \mathrm{Mcal}\right.$ of $\mathrm{NE}_{\mathrm{L}} / \mathrm{kg}$ of $\left.\mathrm{BW}^{0.75}\right)$.

\section{Feedback Parameterization}

Parameterization of the strength of feedback $(\mathrm{k} 1 \times$ $\mathrm{WOL}+\mathrm{k} 2$ ) from energy stores onto DMI predicted by the NRC (2001) equation was undertaken using both descriptions of maintenance. The optimized parameters for each data set, as well as the average for both estimates of maintenance, are presented in Table 2. For both estimates of maintenance, the average $\mathrm{k} 1$ value was negative, indicating that, on average, the strength of the feedback decreased as lactation progressed. Figure 6 shows the strength of the feedback $(\mathrm{k} 1 \times \mathrm{WOL}+$ $\mathrm{k} 2$ ) vs. WOL, and the feedback in kilograms of DMI per day vs. WOL for the time-independent 0.096 maintenance equation.

\section{Evaluation of the Modified Energy Balance Model}

With both sets of average feedback parameters, the mean predicted BW and DMI were not significantly different from observed (Table 3; Figures 7 and 8).

PROC MEANS analysis in SAS shows that 3 of the 4 parameter means are significantly different from 0 (Table 2), and significant improvements in MSPE, overall BW means, DMI means, and analysis of residuals suggest significant improvements in the predictions of BW and DMI with inclusion of the feedback equation. Between the original model (Table 1) and the modified version (Table 3), root MSPE was reduced by $30 \%$ on average for BW predictions and by $23 \%$ for DMI predictions. Inclusion of the feedback reduced the RSS by $52 \%$ for BW predictions and by $41 \%$ for DMI predictions. 

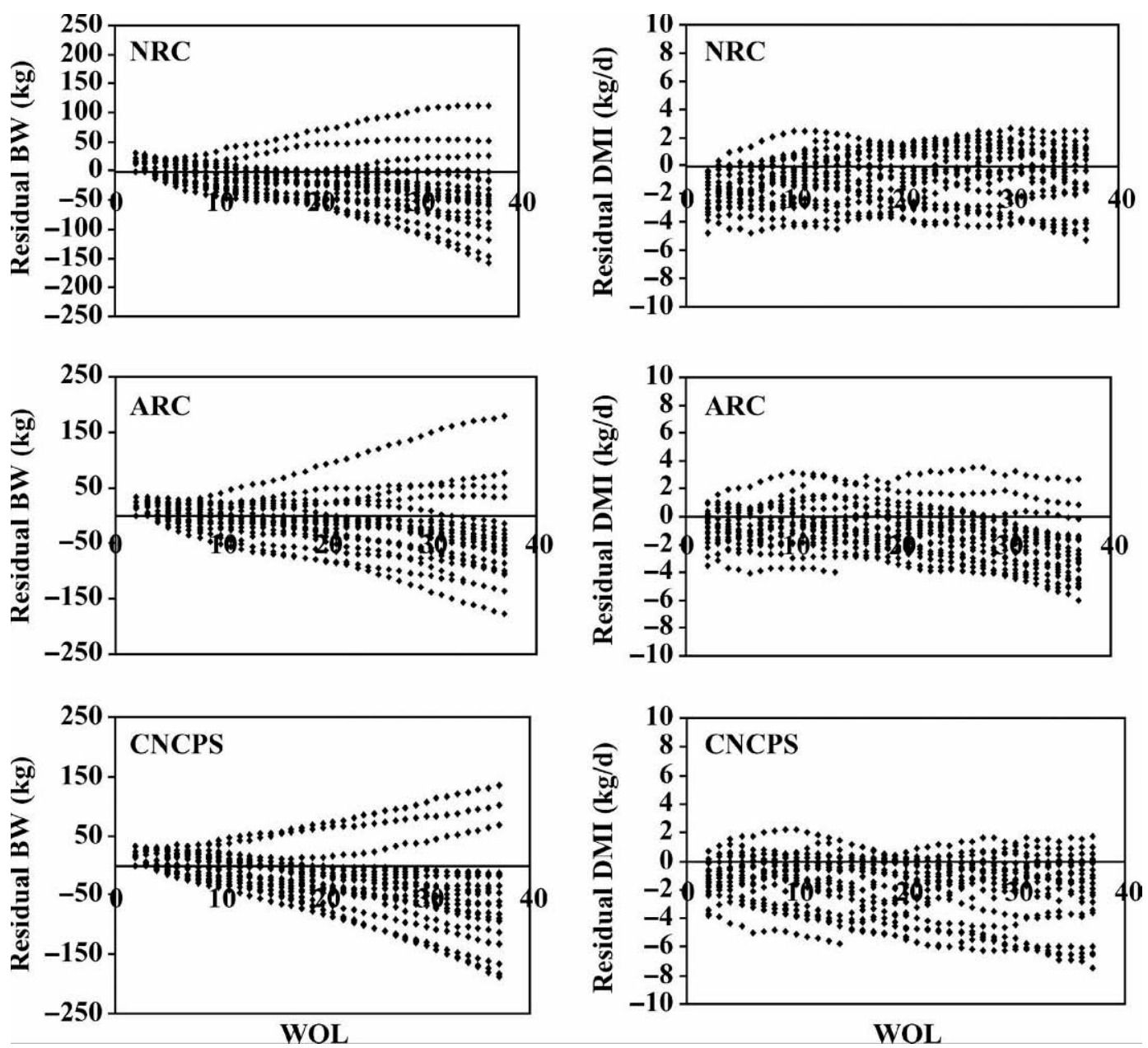

Figure 5. Relationship between residual (predicted - observed) and week of lactation (WOL) for BW (kg; left three graphs) and DMI (kg/d; right three graphs) for the 3 DMI equations [NRC (2001), Agricultural Research Council (ARC; 1980), Cornell Net Carbohydrate and Protein System (CNCPS; Fox et al., 2004)] in the energy balance model (Figure 1a) when maintenance energy expenditures were calculated as a time-dependent equation related to WOL $\left\{\mathrm{NE}_{\mathrm{M}}=\left[-0.0227( \pm 0.0098) \times \mathrm{WOL}^{2}+1.352( \pm 0.456) \times \mathrm{WOL}+78.09( \pm 4.92) \mathrm{Mcal}\right.\right.$ of $\mathrm{NE} / \mathrm{kg}$ of $\left.\left.\mathrm{BW}^{0.75}\right] \times 10^{-3}\right\}$.

Feedback parameter set 1 resulted in the best BW and DMI predictions in terms of root MSPE percentage and RSS (Table 3). The predicted vs. observed regression was not significantly different from the line of unity (Figure 7), and the majority of MSPE was from random sources (Table 3). No significant relationships between residuals and WOL (Figure 7) were detected.

\section{DISCUSSION}

The dynamic modeling of dairy cow performance (e.g., Baldwin et al., 1987) typically requires some sort of lactation curve (Rook et al., 1993; Dijkstra et al., 1997; Vetharaniam et al., 2003) to describe the changing number of active secretory cells in the mammary glands as lactation progresses. The simulated interaction between nutrition and secretory cell number determines lactation performance. If daily DMI throughout lactation is to be input as a series of predicted, and not measured, values, then there are 2 independently derived equations driving model outputs: the lactation curve equation and the DMI prediction equation. If the relationship between these 2 equations is inappropriate, the model is compromised. Specifically, the problem is that when net energy intake, via DMI prediction, and net energy expenditures are both functions of milk yield and BW, then a certain energy balance is implicit in the simple DMI calculation. Our simulations have made the energy balance explicit from 3 common DMI prediction equations and revealed a net energy deficit that accumulates as lactation progresses and biases ongoing predictions of DMI.

Older editions of the NRC (1988) did not use a regression equation to predict DMI, but actually forced a net 
Table 2. Individual and average energy balance feedback ${ }^{1}$ parameters within the model of energy balance optimized using the timeindependent maintenance equation ${ }^{2}$ or the time-dependent maintenance equation ${ }^{3}$

\begin{tabular}{|c|c|c|c|c|c|c|c|c|c|c|c|c|}
\hline \multirow[b]{3}{*}{ Data set } & \multicolumn{4}{|c|}{ Feedback parameter set $1^{2}$} & \multirow[b]{3}{*}{$\mathrm{RSS}^{4}$} & \multirow[b]{3}{*}{$\mathrm{r}^{2}$} & \multicolumn{4}{|c|}{ Feedback parameter set $2^{3}$} & \multirow[b]{3}{*}{ RSS } & \multirow[b]{3}{*}{$\mathrm{r}^{2}$} \\
\hline & & k1 & & $\mathrm{k} 2$ & & & & k1 & & k2 & & \\
\hline & Value & $\begin{array}{l}\text { Approximate } \\
\text { SE }\end{array}$ & Value & $\begin{array}{l}\text { Approximate } \\
\text { SE }\end{array}$ & & & Value & $\begin{array}{l}\text { Approximate } \\
\text { SE }\end{array}$ & Value & $\begin{array}{l}\text { Approximate } \\
\text { SE }\end{array}$ & & \\
\hline 1 & -1.420 & 0.409 & 40.500 & 13.500 & 52.53 & 0.97 & -1.100 & 0.304 & 30.800 & 9.970 & 48.08 & 0.98 \\
\hline 2 & 0.425 & 0.559 & 11.000 & 6.940 & 61.27 & 0.96 & 0.556 & 0.464 & 6.120 & 5.760 & 58.72 & 0.97 \\
\hline 3 & -1.530 & 1.080 & 44.200 & 37.200 & 137.25 & 0.81 & -1.260 & 0.920 & 35.300 & 31.400 & 132.34 & 0.83 \\
\hline $4^{*}$ & 3.690 & 15.000 & 33.000 & 118.000 & 68.63 & 0.95 & 3.260 & 13.200 & 23.200 & 100.000 & 68.50 & 0.95 \\
\hline 5 & -0.095 & 0.013 & -2.570 & 0.176 & 26.10 & 0.99 & 0.002 & 0.021 & -5.700 & 0.262 & 42.79 & 0.99 \\
\hline 6 & -0.274 & 0.034 & 3.910 & 0.533 & 40.48 & 0.99 & -0.117 & 0.394 & 0.361 & 0.587 & 47.92 & 0.98 \\
\hline 7 & 0.077 & 0.035 & -0.117 & 0.447 & 79.94 & 0.95 & 0.140 & 0.035 & -2.630 & 0.413 & 72.90 & 0.96 \\
\hline 8 & 0.242 & 0.058 & 0.750 & 0.887 & 69.38 & 0.97 & 0.348 & 0.060 & -2.840 & 0.798 & 69.69 & 0.97 \\
\hline 9 & 0.162 & 0.034 & -0.025 & 0.417 & 64.56 & 0.97 & 0.272 & 0.060 & -3.010 & 0.758 & 63.25 & 0.97 \\
\hline 10 & 0.333 & 0.045 & -1.540 & 0.941 & 75.53 & 0.96 & 0.489 & 0.046 & -6.620 & 0.711 & 80.74 & 0.96 \\
\hline 11 & -0.340 & 0.059 & 9.840 & 2.400 & 102.54 & 0.92 & -0.210 & 0.044 & 5.750 & 1.820 & 98.62 & 0.93 \\
\hline 12 & 0.092 & 0.026 & 0.747 & 0.330 & 24.35 & 1.00 & 0.218 & 0.036 & -2.660 & 0.424 & 29.59 & 0.99 \\
\hline 13 & -0.173 & 0.018 & 0.282 & 0.265 & 33.39 & 0.99 & -0.051 & 0.051 & -2.960 & 0.354 & 47.89 & 0.98 \\
\hline 14 & -0.249 & 0.126 & 9.050 & 4.640 & 114.77 & 0.91 & -0.095 & 0.082 & 3.850 & 2.960 & 85.83 & 0.95 \\
\hline 15 & -0.265 & 0.075 & 10.300 & 2.750 & 69.05 & 0.97 & -0.113 & 0.047 & 5.840 & 1.710 & 47.04 & 0.99 \\
\hline 16 & -0.737 & 0.228 & 33.600 & 8.770 & 62.36 & 0.98 & -0.514 & 0.174 & 25.800 & 6.620 & 54.19 & 0.98 \\
\hline 17 & -0.621 & 0.298 & 27.300 & 11.200 & 117.50 & 0.92 & -0.407 & 0.230 & 19.800 & 8.530 & 106.89 & 0.93 \\
\hline 18 & -0.544 & 0.261 & 15.800 & 8.110 & 74.69 & 0.95 & -0.254 & 0.156 & 7.360 & 4.750 & 53.51 & 0.97 \\
\hline 19 & 0.186 & 0.025 & 1.160 & 0.588 & 17.91 & 1.00 & 0.446 & 0.025 & -6.240 & 0.433 & 21.10 & 1.00 \\
\hline 20 & -1.020 & 0.294 & 35.700 & 9.260 & 48.25 & 0.98 & -0.723 & 0.210 & 26.400 & 6.510 & 41.22 & 0.99 \\
\hline 21 & -0.338 & 0.073 & 15.600 & 2.200 & 25.20 & 0.99 & -0.005 & 0.031 & 5.780 & 1.000 & 26.94 & 0.99 \\
\hline Average $^{5}$ & -0.304 & 0.122 & 12.774 & 3.40 & & & -0.119 & 0.110 & 7.025 & 2.958 & & \\
\hline
\end{tabular}

${ }^{1}$ Feedback $=[\mathrm{k} 1 \times \mathrm{WOL}+\mathrm{k} 2] \times[(\mathrm{ER}-\mathrm{iER}) / \mathrm{iER}]$, where ER $(\mathrm{Mcal})$ is the integral of $\mathrm{dER} / \mathrm{dt}=\mathrm{NEI}-\mathrm{NE} \mathrm{L}_{\mathrm{L}}-\mathrm{NE}$ [dER/dt $=\mathrm{instantaneous}$ change in body energy reserves per day (net energy balance) and NEI = net energy intake], giving current body energy reserves, and iER is the initial energy reserves, set to $1.11 \times$ initial empty BW according to the relationship between BCS and fat content of the empty body developed by Fox et al. (1999) for a BCS of 3.5. Estimates of k1 and k2 feedback parameters were obtained for each of the 21 data sets with an iterative Levenberg-Marquardt algorithm to find lowest residual sums of squares between predicted and observed weekly BW across 35 wk of lactation (WOL).

${ }^{2}$ Maintenance energy expenditures were calculated as $\mathrm{NE}_{\mathrm{M}}=0.096 \mathrm{Mcal}$ of $\mathrm{NE}_{\mathrm{L}} / \mathrm{kg}$ of $\mathrm{BW}^{0.75}$

${ }^{3}$ Maintenance energy expenditures were calculated as $\mathrm{NE}_{\mathrm{M}}=\left[-0.0227( \pm 0.0098) \times \mathrm{WOL}^{2}+1.352( \pm 0.456) \times \mathrm{WOL}+78.09( \pm 4.92) \mathrm{Mcal}\right.$ of $\mathrm{NE}_{\mathrm{L}} / \mathrm{kg}$ of $\left.\mathrm{BW}^{0.75}\right] \times 10^{-3}$.

${ }^{4} \mathrm{RSS}=$ residual sum of squares $\left[\Sigma(\text { predicted }- \text { observed })^{2}\right]$.

${ }^{5}$ Average SE are calculated from the k parameters, not an average of the approximate SE. PROC MEANS shows k1 and k2 from parameter set 1 are significant $(P=0.0221$ and 0.0013 , respectively) and $\mathrm{k} 2$ from parameter set 2 is significant $(P=0.0282)$.

*Values were not included in average.

energy balance of 0 by calculating DMI from net energy requirements and net energy content of the feed. This approach, however, does not allow for prediction of the surplus or deficit of net energy that is deposited or withdrawn from body stores, which constitutes an important component of lactation performance to be predicted. Because of the accumulation of small errors over time with dynamic simulations and where DMI influences BW change and BW change in turn influences DMI, any DMI regression equation, no matter how tightly fit to a set of static observations, is prone to generate inappropriate energy balances in the long term. As a general solution to prevent predicted BW from deviating substantially over time from the observed BW, a lipostatic mechanism was selected to be included in the dynamic model of energy balance. To illustrate the approach, the NRC (2001) DMI prediction equation was chosen as paradigmatic of the regression type equation, according to the definitions of Ingvartsen (1994), but the feedback approach would be amenable to application with any such equation. Similarly, the results of our parametization are unique to the sets of data used, particularly given that a mean bias in estimated energy balance was corrected by revising $\mathrm{NE}_{\mathrm{M}}$ expenditures (Ellis et al., 2006).

The lipostatic theory states that the cow has a BW set point, or desired level of body fatness, which it will defend by modifying DMI. The BW set point has been demonstrated in the recovery response following experimentally induced changes in BW in which animals return to a BW that is appropriate for their age, stage of development, environment, or any combination of these factors (Keesey and Hirvonen, 1997). It is important to note that the BW set point theory applies over long periods of time and regulates energy balance on a longterm basis. Thus, the recovery of $\mathrm{BW}$ in late lactation 

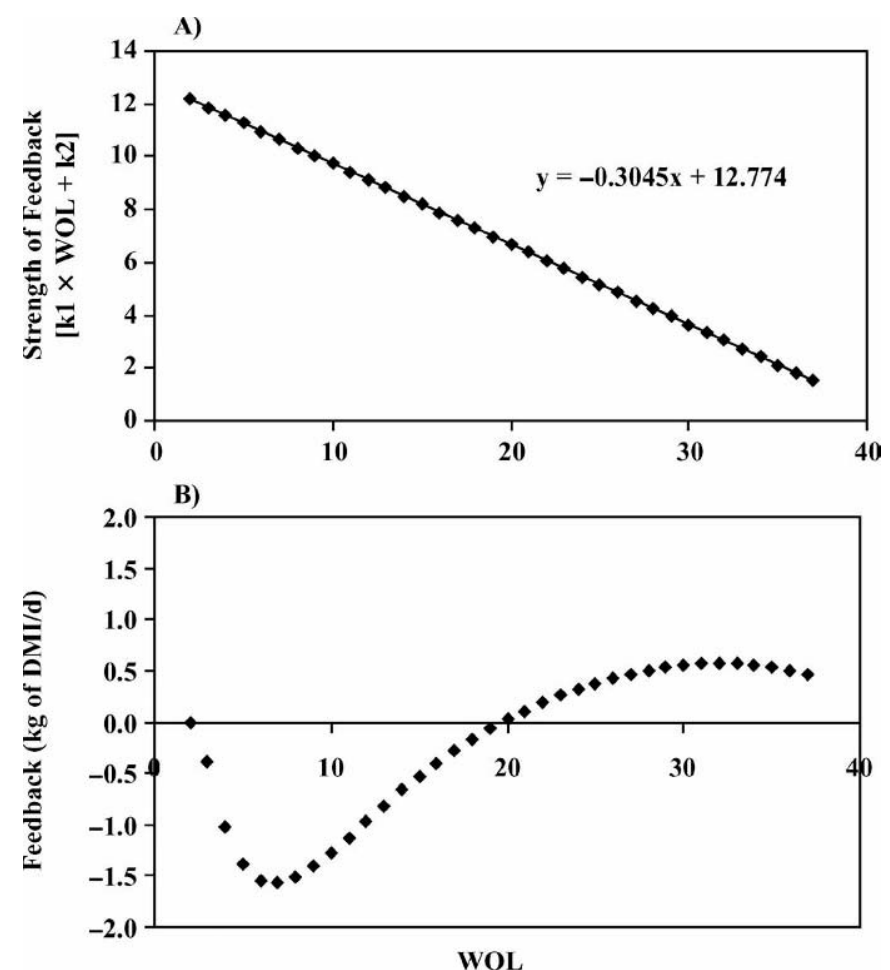

Figure 6. Strength of feedback $(\mathrm{k} 1 \times \mathrm{WOL}+\mathrm{k} 2)$ vs. WOL (top) and feedback $[(\mathrm{k} 1 \times \mathrm{WOL}+\mathrm{k} 2) \times[(\mathrm{ER}-\mathrm{iER}) /(\mathrm{iER})]] \mathrm{vs}$. WOL (bottom) for the 0.096 time-independent maintenance equation (Mcal of $\mathrm{NE}_{\mathrm{L}}$ / $\mathrm{kg}$ of $\mathrm{BW}^{0.75}$ ) run in the dynamic model of energy balance (Figure 1b) with feedback parameter set 1. WOL $=$ Week of lactation; ER $(\mathrm{Mcal})=$ integral of $\mathrm{dER} / \mathrm{dt}=\mathrm{NEI}-\mathrm{NE}_{\mathrm{L}}-\mathrm{NE}_{\mathrm{M}}[\mathrm{dER} / \mathrm{dt}=$ instantaneous change in body energy reserves per day (net energy balance) and NEI = net energy intake], giving current body energy reserves; $\mathrm{iER}=$ initial energy reserves, set to $1.11 \times$ initial empty BW according to the relationship between BCS and fat content of the empty body developed by Fox et al. (1999) for a BCS of 3.5. Estimates of k1 and k2 feedback parameters were obtained for each of the 21 data sets with an iterative Levenberg-Marquardt algorithm to find lowest residual sums of squares between predicted and observed weekly BW across 35 WOL.

cows after an initial loss to support peak levels of milk production can be considered a lipostatic response.

In our use of the lipostatic theory, we have assumed that the BW set point is constant over the course of lactation and is expressed as the size of body energy reserves at the onset of lactation. In preliminary simulations, setting the $\mathrm{BW}$ set point to the observed $\mathrm{BW}$ at the end of lactation resulted in similar behavior of the feedback. According to the formation of the feedback in Equation 8, the rate at which energy stores return to the set point is governed by the size of the term $\mathrm{k} 1$ $\times$ WOL $+\mathrm{k} 2$, which we refer to as the strength of the feedback. Initially, a constant strength across WOL was attempted with a parameter $\mathrm{k}$ in place of $\mathrm{k} 1 \times \mathrm{WOL}+$ $\mathrm{k} 2$. However, the least squares estimates of $\mathrm{k}$ were so high that predicted BW did not deviate from the initial or set point BW for the entire lactation (data not shown). It was hypothesized that the strength of the feedback needed to change during the course of lactation to allow $\mathrm{BW}$ to deviate from the set point enough to mimic actual BW changes. A continuous, linear equation related to WOL allowed BW to deviate to the degree demonstrated in the 21 sets of evaluation data. For all scenarios examined, the slope of the energy stores feedback in relation to WOL, or the desire to maintain BW at the set point, was negative. In terms of physiology, this means that as lactation progressed, the strength of the feedback became weaker.

One of the most important metabolic changes that occurs in a cow to support milk production is the decreased uptake of nutrients for lipid synthesis by the adipose tissue and the increased mobilization of lipid reserves (Bauman and Currie, 1980). The net result is a favored partitioning of nutrients toward the mammary glands rather than maintaining body energy stores. These changes in the partitioning of nutrients are of the greatest magnitude and greatest importance at the onset of lactation. Thus, it was expected that the strength of the feedback of energy stores on DMI would relax during early lactation and would increase as lactation progressed.

Explanation for why the slope of the feedback was negative in this study, contrary to expectation, has 2 parts. First, for the majority of data sets used for estimating $\mathrm{k} 1$ and $\mathrm{k} 2$, BW did not decrease substantially during early lactation. This means that the feedback did not need to relax during early lactation. There is error in using BW change to represent mobilization of energy stores in early lactation. When DMI is increasing at the same time that energy stores are being depleted, body energy stores can change by $40 \%$ with no change in BW (Chilliard et al., 1991; Gibb et al., 1992; Komaragiri and Erdman, 1997; NRC, 1988; Komaragiri et al., 1998). The availability of BCS data might have allowed a more accurate estimate of changes in the strength of an adipose feedback on DMI.

The second reason for a negative slope was that BW increased as lactation progressed. Body weight at the end of the evaluation period was on average $6.4 \%$ higher than the initial BW (ranging from -2 to $+18 \%$ ). Ten of the 21 herds in the evaluation data set were composed of entirely primiparous animals, and 5 were a mix of primiparous and multiparous cows. Continued growth in these animals caused BW at the end of lactation to be higher than at the onset. To allow BW to increase during late lactation, the feedback needed to relax at progressive WOL.

Regardless of the confounded physiological interpretation of the parameters, the actual feedback in kilograms of DMI per days followed the expected pattern 
Table 3. Statistics of BW and DMI predictions of the dynamic model with inclusion of the feedback of body energy stores onto DMI, using the NRC (2001) DMI equation and the two new descriptions of maintenance energy expenditures during lactation

\begin{tabular}{|c|c|c|c|c|c|c|c|c|c|}
\hline \multirow[b]{2}{*}{ Prediction } & \multirow[b]{2}{*}{ Maintenance description } & \multirow[b]{2}{*}{ Feedback } & \multicolumn{2}{|c|}{ Predicted } & \multirow{2}{*}{$\begin{array}{l}\text { Root } \\
\text { MSPE }^{1}\end{array}$} & \multicolumn{3}{|c|}{ MSPE } & \multirow[b]{2}{*}{$\operatorname{RSS}^{5}$} \\
\hline & & & Mean & SEM & & $\mathrm{ECT}^{2}$ & $\mathrm{ER}^{3}$ & $\mathrm{ED}^{4}$ & \\
\hline & & & & & & $-(\%)$ & & & \\
\hline & Time-dependent maintenance equation 8 & Parameter set $2^{9}$ & 564.6 & 2.6 & 5.4 & 5.0 & 33.5 & 61.7 & 694,129 \\
\hline DMI & Time-independent equation ${ }^{6}$ & Parameter set $1^{7}$ & 17.3 & 0.1 & 8.8 & 2.2 & 27.0 & 70.9 & 1,815 \\
\hline & Time-dependent maintenance equation 8 & Parameter set $2^{9}$ & 17.1 & 0.1 & 8.9 & 7.7 & 24.4 & 68.0 & 1,831 \\
\hline
\end{tabular}

${ }^{1}$ Root mean square prediction error (MSPE) expressed as a percentage of the observed mean.

${ }^{2}$ Error due to bias; percentage of total MSPE.

${ }^{3}$ Error due to regression; percentage of total MSPE.

${ }^{4}$ Error due to disturbance; percentage of total MSPE.

${ }^{5} \mathrm{RSS}=$ residual sum of squares $\left[\Sigma(\text { predicted }- \text { observed })^{2}\right]$.

${ }^{6}$ Maintenance energy expenditures calculated as $\mathrm{NE}_{\mathrm{M}}=0.096 \mathrm{Mcal}$ of $\mathrm{NE}_{\mathrm{L}} / \mathrm{kg}$ of $\mathrm{BW}^{0.75}$.

${ }^{7}$ Feedback equation $1=[-0.304( \pm 1.187) \times$ WOL $+12.77( \pm 5.578)] \times[($ ER - iER $) /$ iER $]$, where WOL $=$ week of lactation; optimized using the 0.096 time-independent maintenance equation (see Table 2).

${ }^{8}$ Maintenance energy expenditures was calculated as $\mathrm{NE}_{\mathrm{M}}=\left[-0.0227( \pm 0.0098) \times \mathrm{WOL}^{2}+1.352( \pm 0.456) \times \mathrm{WOL}+78.09( \pm 4.92) \mathrm{Mcal}\right.$ of $\mathrm{NE}_{\mathrm{L}} / \mathrm{kg}$ of $\left.\mathrm{BW}^{0.75}\right] \times 10^{-3}$.

${ }^{9}$ Feedback equation $2=[-0.119( \pm 0.169) \times$ WOL $+7.025( \pm 4.289)] \times[(\mathrm{ER}-\mathrm{iER}) / \mathrm{iER}]$, optimized using the time-dependent maintenance equation (see Table 2).

of an inhibitory or negative effect in early lactation and a positive effect later on (Figure $6 \mathrm{~b}$ ). The net feedback is due to both the strength of the signal emanating from body energy stores and the total size of body stores themselves, which is lower in early than in late lactation.

Significant variation existed between feedback parameters, fitted from individual data sets, within each
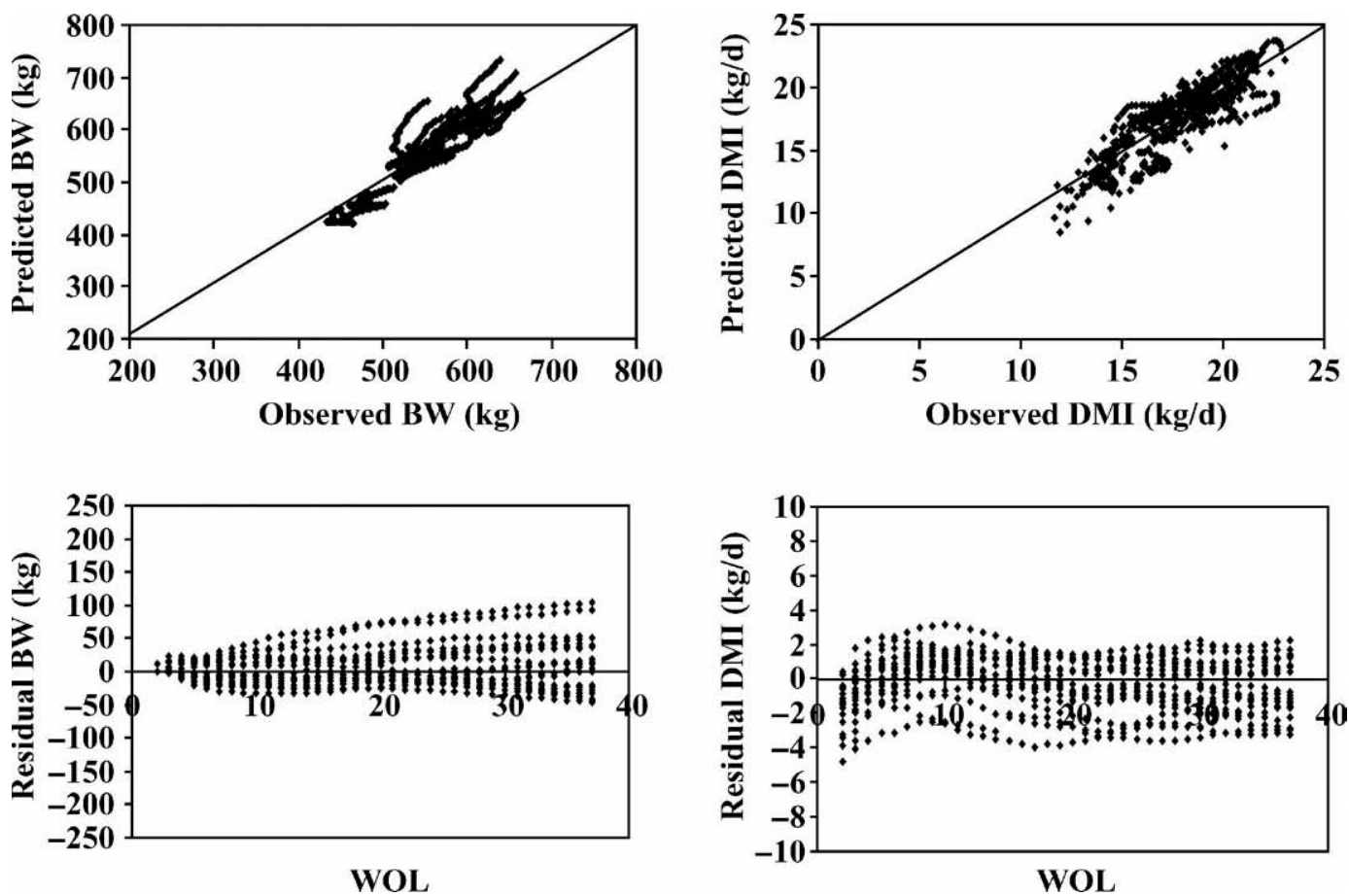

Figure 7. Predicted vs. observed (top) and residual (predicted - observed) vs. week of lactation (WOL; bottom) for BW (kg; left side) and DMI (kg/d; right side) in the energy balance model (Figure 1b) with the NRC (2001) DMI equation when maintenance energy expenditures were calculated as a time-independent equation $\left(0.096 \mathrm{Mcal}\right.$ of $\mathrm{NE}_{\mathrm{L}} / \mathrm{kg}$ of $\left.\mathrm{BW}^{0.75}\right)$ and using feedback parameter set 1. 

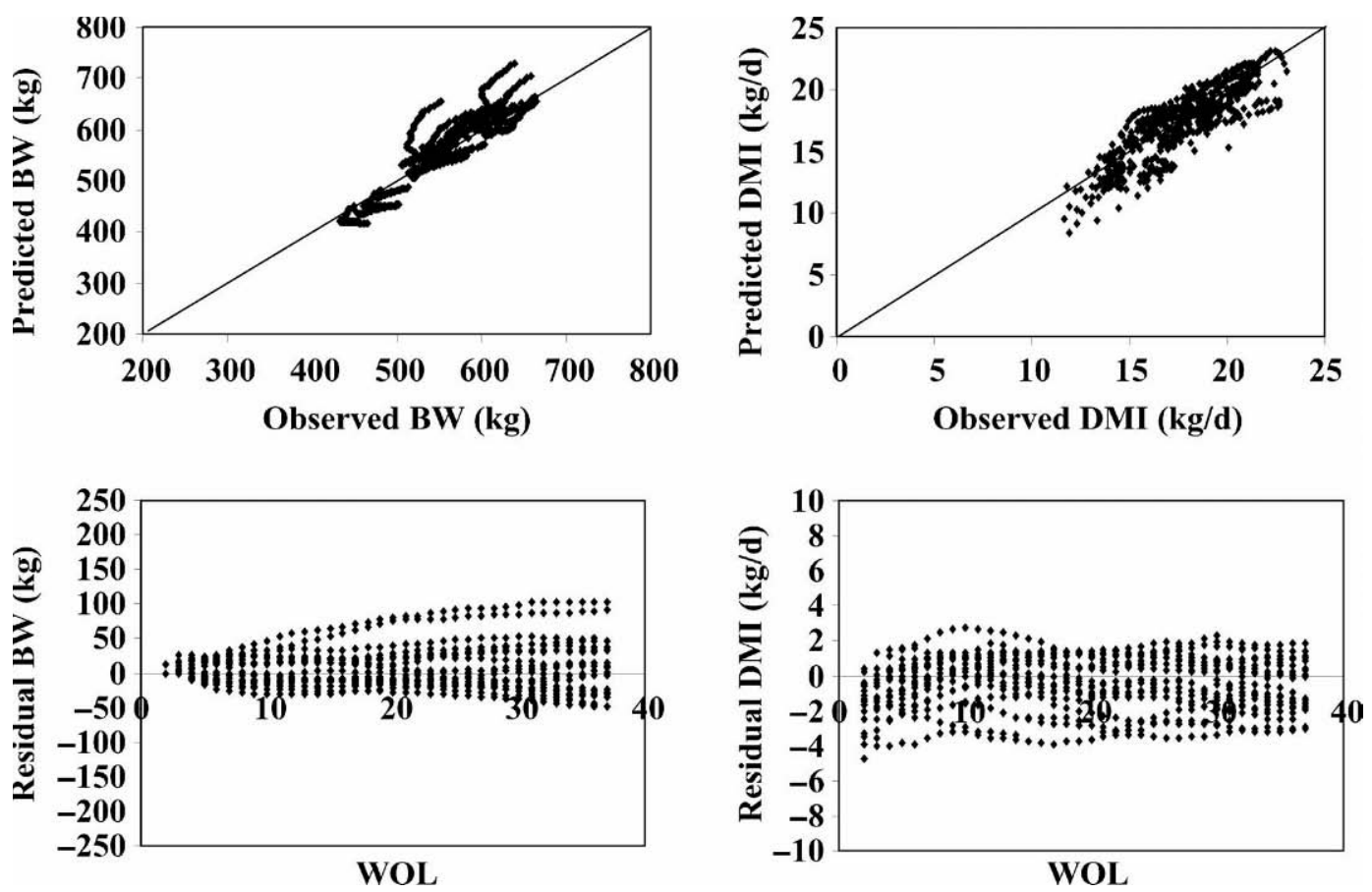

Figure 8. Predicted vs. observed (top) and residual (predicted - observed) vs. week of lactation (WOL; bottom) for BW (kg; left side) and DMI (kg/d; right side) in the energy balance model (Figure 1b) with the NRC (2001) DMI equation when maintenance energy expenditures were calculated as $\mathrm{NE}_{\mathrm{M}}=\left[-0.0227( \pm 0.0098) \times \mathrm{WOL}^{2}+1.352( \pm 0.456) \times \mathrm{WOL}+78.09( \pm 4.92) \mathrm{Mcal}\right.$ of $\mathrm{NE}_{\mathrm{L}} / \mathrm{kg}$ of $\left.\mathrm{BW}^{0.75}\right] \times 10^{-3}$ and using feedback parameter set 2 .

description of maintenance (Table 2). A large part of the variation in feedback parameters was due to using a single set of parameters to describe $\mathrm{NE}_{\mathrm{M}}$ for all data sets. The magnitude of $\mathrm{NE}_{\mathrm{M}}$ was increased over the NRC (2001) recommendation as a means to correct a mean bias in cumulative energy balance detected by our method of BW evaluation. A slope bias and random error remained such that estimated $\mathrm{NE}_{\mathrm{M}}$ varied $25 \%$ around the proposed mean equations (Ellis et al., 2006). This remaining error was transferred into the feedback parameters. When individual maintenance parameters fit from each of the 21 data sets were utilized in feedback equation parameterization, variation in feedback parameters was significantly reduced (data not shown), although the strength of feedback slope remained negative. However, the practicality of a lipostatic feedback approach based on individual maintenance descriptions that are difficult to obtain is low.

Introduction of an average-sized feedback of energy stores onto DMI solved the problem of unrealistic BW within a dynamic model of energy balance that was driven by independently derived lactation curve and DMI prediction equations. Residual sum of squares was reduced on average by $52 \%$ for BW predictions and by $41 \%$ for DMI predictions. Similarly, root MSPE was reduced by $30 \%$ on average for $\mathrm{BW}$ predictions and by $23 \%$ for DMI predictions. The 0.096 maintenance equation combined with feedback parameter set 1 resulted in the best overall BW and DMI predictions within the dynamic energy balance model.

\section{CONCLUSIONS}

Evaluation of the $3 \mathrm{DMI}$ prediction equations (ARC, 1980; Fox et al., 2004; NRC, 2001) within the energy balance model showed that the NRC (2001) DMI equation yielded the best BW and DMI predictions based on MSPE and RSS analysis. Modification of the energy balance model with creation of a negative feedback of energy stores onto DMI introduced the effects of adiposity onto DMI predictions. This significantly improved prediction of DMI and BW within the dynamic energy balance model, resulting in BW and DMI predictions not significantly different from observed values. Overall, inclusion of the feedback prevented errors from accumulating in BW over time by making small adjustments to DMI, improving both BW and DMI predictions. The approach could be useful in dynamic modeling of dairy cow performance where predictions of both milk production and DMI may be required. 


\section{ACKNOWLEDGMENTS}

The authors thank Mike Messman and Richard Spratt from Cargill Animal Nutrition for their efforts throughout this project. This work was funded by a grant-in-aid from Agribrands International, a wholly owned subsidiary of Cargill, Inc., NSERC Canada, and the Ontario Ministry of Agriculture and Food.

\section{REFERENCES}

Advanced Continuous Simulation Language (ACSL). 1994-1998. AEgis Simulation Inc., Huntsville, AL.

Agricultural Research Council. 1980. The Nutrient Requirements of Ruminant Livestock-Technical Review by an Agricultural Research Council Working Party. Commonwealth Agricultural Bureaux, Slough, UK.

Baldwin, R. L., J. France, D. E. Beever, M. Gill, and J. H. M. Thornley. 1987. Metabolism of the lactating cow III. Properties of mechanistic models suitable for evaluation of energetic relationships and factors involved in the partition of nutrients. J. Dairy Res. 54:133-145.

Bauman, D. E., and W. B. Currie. 1980. Partitioning of nutrients during pregnancy and lactation: A review of mechanisms involving homeostasis and homeorhesis. J. Dairy Sci. 63:1514-1529.

Bibby, J., and H. Toutenburg. 1977. Prediction and Improved Estimation in Linear Models. John Wiley \& Sons, Chichester, UK.

Bines, J. A. 1979. Voluntary Food Intake. Pages 23-48 in Feeding Strategy for the High Yielding Dairy Cow. W. H. Broster, and H. Swan, ed. Granada Publishing, London, UK.

Broster, W. H., and V. J. Broster. 1998. Body score of dairy cows. J. Dairy Res. 65:155-173.

Chilliard, Y., M. Cisse, R. LeFaivre, and B. Remond. 1991. Body composition of dairy cows according to lactation stage, somatotropin treatment, and concentrate supplementation. J. Dairy Sci. 74:3103-3116.

Coppock, C. E., C. H. Noller, S. A. Wolfe, C. J. Callahan, and J. S. Baker. 1972. Effect of forage-concentrate ratio in complete feeds fed ad libitum on feed intake prepartum and the occurrence of abomasal displacement in dairy cows. J. Dairy Sci. 55:783-789.

Dijkstra, J., J. France, M. S. Dhanoa, J. A. Maas, M. D. Hanigan, A. J. Rook, and D. E. Beever. 1997. A model to describe growth patterns of the mammary gland during pregnancy and lactation. J. Dairy Sci. 80:2340-2354.

Dijkstra, J., J. France, H. D. St. C. Neal, A. G. Assis, L. J. M. Aroeira, and O. F. Campos. 1996. Simulation of digestion in cattle fed sugarcane: Model development. J. Agric. Sci. 127:231-246.

Ellis, J. L., F. Qiao, and J. P. Cant. 2006. Evaluation of net energy expenditures of dairy cows according to body weight changes over a full lactation. J. Dairy Sci. 89:1546-1557.
Fox, D. G., T. P. Tylutki, L. O. Tedeschi, M. E. Van Amburgh, L. E. Chase, A. N. Pell, T. R. Overton, and J. B. Russell. 2004. The Net Carbohydrate and Protein System for evaluating herd nutrition and nutrient excretion. Anim. Feed Sci. Technol. 112:29-78.

Fox, D. G., M. E. Van Amburgh, and T. P. Tylutki. 1999. Predicting requirements for growth, maturity, and body reserves in dairy cattle. J. Dairy Sci. 82:1968-1977.

Garnsworthy, P. C. 1988. The effect of energy reserves at calving on performance of dairy cows. Pages 157-170 in Nutrition and Lactation in the Dairy Cow. P. C. Garnsworhty, ed. Butterworths, London, UK.

Gibb, M. J., W. E. Irvings, M. S. Dhanoa, and J. D. Sutton. 1992. Changes in body components of autumn-calving Holstein Friesian cows over the first 29 weeks of lactation. Anim. Prod. 55:339-360.

Ingvartsen, K. L. 1994. Models of voluntary food intake in cattle. Livest. Prod. Sci. 39:19-38.

Ingvartsen, K. L., A. Danfaer, P. H. Andersen, and J. Foldager. 1995. Prepartum feeding of dairy cattle: A review of the effect on prepartum metabolism, feed intake, production and health. Page 83 in Book of Abstracts of the 46th Annual Meeting of the EAAP, Pragh. J. A. M. Arendonk, ed. Wageningen Press, Wageningen, The Netherlands.

Keesey, R. E., and M. D. Hirvonen. 1997. Body weight set-points: Determination and adjustment. J. Nutr. 127:1875S-1883S.

Kennedy, G. C. 1953. The role of depot fat in the hypothalamic control of food intake in the rat. Proc. R. Soc. Ser. B 139:578-592.

Komaragiri, M. V. S., D. P. Casper, and R. A. Erdman. 1998. Factors affecting body tissue mobilization in early lactation dairy cows. 2. Effect of dietary fat on mobilization of body fat and protein. J. Dairy Sci. 81:169-175.

Komaragiri, M. V. S., and R. A. Erdman. 1997. Factors affecting body tissue mobilization in early lactation dairy cows. 1 . Effect of dietary protein on mobilization of body fat and protein. J. Dairy Sci. 80:929-937.

National Research Council. 1987. Nutrient Requirements of Dairy Cattle. Natl. Acad. Press, Washington, DC.

National Research Council. 1988. Nutrient Requirements of Dairy Cattle. Natl. Acad. Press, Washington, DC.

National Research Council. 2001. Nutrient Requirements of Dairy Cattle. Natl. Acad. Press, Washington, DC.

Rook, A. J., J. France, and M. S. Dhanoa. 1993. On the mathematical description of lactation curves. J. Agric. Sci. 121:97-102.

SAS Institute. 2000. SAS User's Guide. Statistics. SAS Inst., Inc., Cary, NC.

Van der Honing, Y. 1998. Perspectives of future feed information based on energy and nutrient availability. Arch. Tierernahr. 51:135-153.

Vetharaniam, I., S. R. Davis, M. Upsdell, E. S. Kolver, and A. B. Pleasants. 2003. Modeling the effect of energy status on mammary gland growth and lactation. J. Dairy Sci. 86:3148-3156.

Zhang, Y., R. Proenca, M. Maffei, M. Barone, L. Leopold, and J. M. Friedman. 1994. Positional cloning of the mouse obese gene and its human homologue. Nature 372:425-432. 